\title{
Acute Hydrocephalus Following Aneurysmal Subarachnoid Hemorrhage
}

\author{
V. Mehta, R.O. Holness, K. Connolly, S. Walling and R. Hall
}

\begin{abstract}
Background: Acute hydrocephalus is a potentially treatable cause of early neurological deterioration after aneurysmal subarachnoid hemorrhage (SAH). Methods: A retrospective study of 105 consecutive cases of aneurysmal SAH was undertaken to determine those factors significantly related to the development of acute hydrocephalus. Acute hydrocephalus was diagnosed when the bicaudate index was greater than the $95^{\text {th }}$ percentile for age on a CT scan within 72 hours of the ictus. Results: Thirty-one percent of the patients developed acute hydrocephalus. Grade of SAH was a significant factor for the development of acute hydrocephalus on univariate analysis as $87 \%$ of patients with acute hydrocephalus (29/32) presented with at least grade 3 (Hunt-Hess) SAH ( $<<0.05$ ). In addition, posterior circulation aneurysms on univariate analysis were associated with acute hydrocephalus $(\mathrm{p}<0.05)$. Both premorbid hypertension and intraventricular blood $(\mathrm{p}<0.05)$ were predictors for acute hydrocephalus, whereas intracisternal blood, age and sex were not. On multivariate linear regression analysis, factors found to be significantly associated with acute hydrocephalus were premorbid hypertension, intraventricular blood, CSF diversion and definitive shunt procedures. External ventricular drainage was not associated with any instances of rebleeding. Thirty-seven percent (10/27) of patients with acute hydrocephalus who survived were improved by pre-operative external ventricular drainage. Conclusions: Patients with acute hydrocephalus following SAH can be safely treated with external ventricular drainage. Multiple factors can be identified to predict those patients who will develop acute hydrocephalus post aneurysmal rupture. Approximately $30 \%$ of those patients with acute hydrocephalus will require definitive shunt placement. Acute hydrocephalus occurred in $31 \%$ of aneurysmal SAH patients in this series.
\end{abstract}

RÉSUMÉ: Hydrocéphalie aiguë consécutive à une hémorragie sous-arachnoïdienne. Introduction: L'hydrocéphalie aiguë est une cause traitable de détérioration neurologique précoce suite à une hémorragie sous-arachnoïdienne (HSA) due à un anévrisme. Méthodes: Nous avons procédé à une étude rétrospective de 105 cas consécutifs d'HSA anévrismale afin d'identifier les facteurs significativement reliés au développement de l'hydrocéphalie aiguë. Un diagnostic d'hydrocéphalie aiguë était posé quand l'indice bicaudal était supérieur au $95^{\mathrm{e}}$ percentile pour l'âge sur le CT scan fait dans les 72 heures de l'ictus. Résultats: Trente-et-un pourcent des patients ont développé une hydrocéphalie aiguë. Le grade de l'HSA était un facteur significatif du développement d'une hydrocéphalie aiguë à l'analyse bivariée, $87 \%$ des patients avec hydrocéphalie aiguë (29/32) ayant présenté une HSA de grade 3 (Hunt-Hess) ou plus au moment de la consultation initiale $(p<0.05)$. De plus, les anévrismes impliquant la circulation postérieure étaient associés avec une hydrocéphalie aiguë $(p<0.05)$ à l'analyse univariée. Une hypertension prémorbide et la présence de sang intraventriculaire $(\mathrm{p}<0.05)$ étaient des prédicteurs de l'hydrocéphalie aiguë, alors que la présence de sang intracisternal, l'âge et le sexe ne l'étaient pas. À l'analyse multivariée, les facteurs associés de façon significative à l'hydrocéphalie aiguë étaient l'hypertension prémorbide, la présence de sang intraventriculaire, une dérivation du LCR et un shunt permanent. Le drainage ventriculaire externe n'était pas associé au resaignement. Trente-sept pourcent (10/27) des patients avec hydrocéphalie aiguë qui ont survécu ont été améliorés par un drainage ventriculaire externe préopératoire. Conclusions: On peut procéder en toute sécurité à un drainage ventriculaire externe chez les patients présentant une hydrocéphalie aiguë suite à une HSA. On peut identifier plusieurs facteurs prédictifs d'une hydrocéphalie aiguë après la rupture d'un anévrisme. À peu près $30 \%$ des patients avec une hydrocéphalie aiguë vont nécessiter la mise en place d'un shunt permanent. Dans notre étude, trente-et-un pourcent des patients ayant une HSA d'origine anévrismale ont présenté une hydrocéphalie aiguë.

Can. J. Neurol. Sci. 1996; 23: 40-45

Recognition and treatment of acute hydrocephalus in the early stages following aneurysmal subarachnoid hemorrhage (SAH), has become a valuable peri-operative strategy.

The incidence (9-67\%) of acute hydrocephalus varies depending on the population studied and the definition used. . $^{2-9}$ Most studies, including the Cooperative study, ${ }^{4}$ have placed this incidence between 15 and $20 \%$.

The mechanism of acute hydrocephalus may be related to decreased absorption of cerebrospinal fluid (CSF) because of structural blockage of the arachnoid villi by erythrocytes. ${ }^{10}$

From the Division of Neurosurgery and Department of Anacsthesia. Dalhousie University, Victoria General Hospital, Halifax.

RECEIVED JANUARY 3, 1995. ACCEPTED IN FINAL FORM SEPTEMBER I I, 1995.

Reprint requests to: Dr. R.O. Holness, Division of Neurosurgery, Rm. 2-111, Centennial Wing, Victoria General Hospital, Halifax. Nova Scotia. Canada B3H 2 Y9 
Clots in the subarachnoid space resorb more slowly than in other parts of the body. Injection of intracisternal heparinized blood in monkeys revealed normal CSF outflow, whereas nonheparinized blood was associated with increased outflow resistance of CSF flow. This has suggested that fibrin deposition plays a role in reduction of CSF flow and absorption. ${ }^{11}$

Bagley related meningeal thickening caused by subarachnoid hemorrhage to the development of acute hydrocephalus. ${ }^{12}$

In a series of 42 patients, radioisotope cisternography revealed impairment of CSF flow that correlated well with deterioration in neurological status. In this study, however, assays of erythrocytes in the CSF did not correlate with disturbances of CSF flow. The following study promoted the hypothesis that fibrin, rather than erythrocytes, may be responsible for obstruction at the arachnoid villi. ${ }^{13}$

The pathogenesis of hydrocephalus following SAH has been recently reviewed by Marcuso and Wenstein. ${ }^{14}$

We defined acute hydrocephalus radiolographically as a bicaudate index above the 95th percentile for age on the CT scan within $72 \mathrm{hrs}$ of the ictus. We studied the relationship between acute hydrocephalus and the following factors: age, sex, grade of SAH, site of aneurysm, intraventricular (IV) blood, intracisternal (IC) blood, pre-morbid hypertension, and the performance of perioperative cerebrospinal fluid (CSF) diversion (external ventricular drainage (EVD), or lumbar drainage) and post-operative ventriculo-peritoneal (VP) shunt).

\section{METHODS}

We reviewed the medical records of 105 consecutive patients with aneurysmal SAH who presented to our institution within 72 hours of their ictus, between July, 1989, and December, 1993.

All patients had clinical evidence of SAH and underwent computerized axial tomography (CT) within $72 \mathrm{hrs}$ of their hemorrhage. Scans were analysed for the width of the frontal horns at the level of the caudate nuclei and this value was divided by the diameter of the brain at the same level. For each patient the resulting bicaudate index was then compared to the upper normal $\left(95^{\text {th }}\right.$ percentile) limits matched for age $(<36 \mathrm{yrs}=$ $0.16 ; 36-45 \mathrm{yrs}=0.17 ; 46-55 \mathrm{yrs}=0.18 ; 56-65 \mathrm{yrs}=0.19 ; 66$ $75 \mathrm{yrs}=0.20 ; 76-85 \mathrm{yrs}=0.21){ }^{6}$ The technique for determining the bicaudate index is illustrated in Figures 1 and 2.

For inclusion in this study, all patients had to have radiological signs of SAH. 101 patients had angiography which demonstrated the ruptured aneurysm. Four patients with grade V SAH did not have angiography but were included in the study as the distribution of blood on the CT scan was typical for an aneurysmal rupture. This avoided selection bias against those with grade $\mathrm{VSAH}$ in which conservative treatment was undertaken and angiography not performed.

The CT scans were then reviewed (V.M., S.W.) and the grading system of Van Gijn et al. ${ }^{15}$ was employed to grade hydrocephalus as well as intraventricular (IV) and cisternal blood. IV blood was graded out of a total score of 12 with each of the four ventricles assigned a score of 0 to 3 depending on whether there was no blood, sedimentation of blood, the ventricle was partially full of blood, or the ventricle was full of blood.

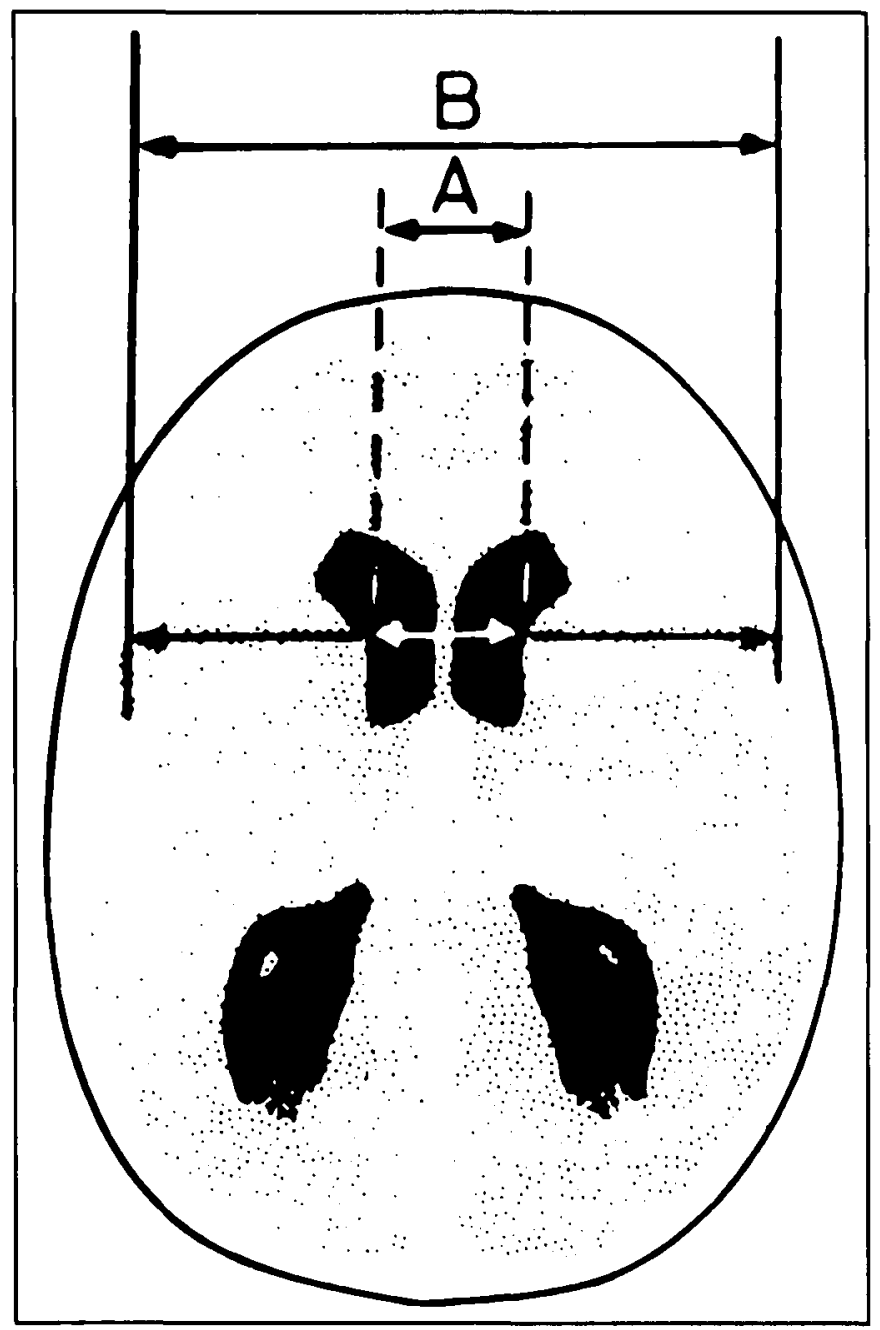

Figure 1: Diagram showing the method for measuring the bicaudate index $(A \div B) . A=$ the width of the frontal horns at the level of the can. date nuclei; $B=$ the diameter of the brain at the same level. (Reproduced by permission - Van Gijn, et al.: Acute hydrocephalus after aneurysmal subarachnoid hemorrhage. J Neurosurg 1985: 63: 355-362.)

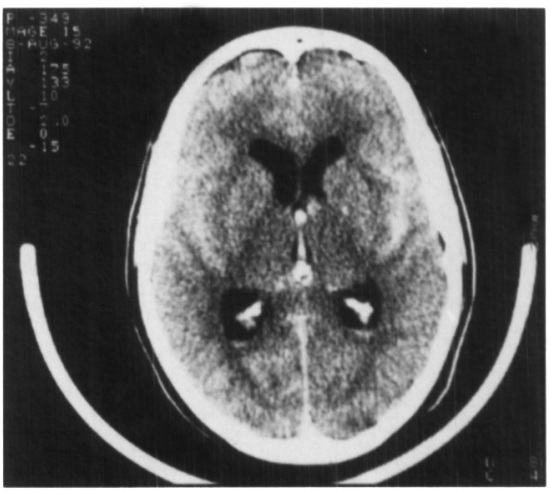

Figure 2: Illustrating CT scan of a patient with actute hydrocephalus following aneurysmal SAH. 


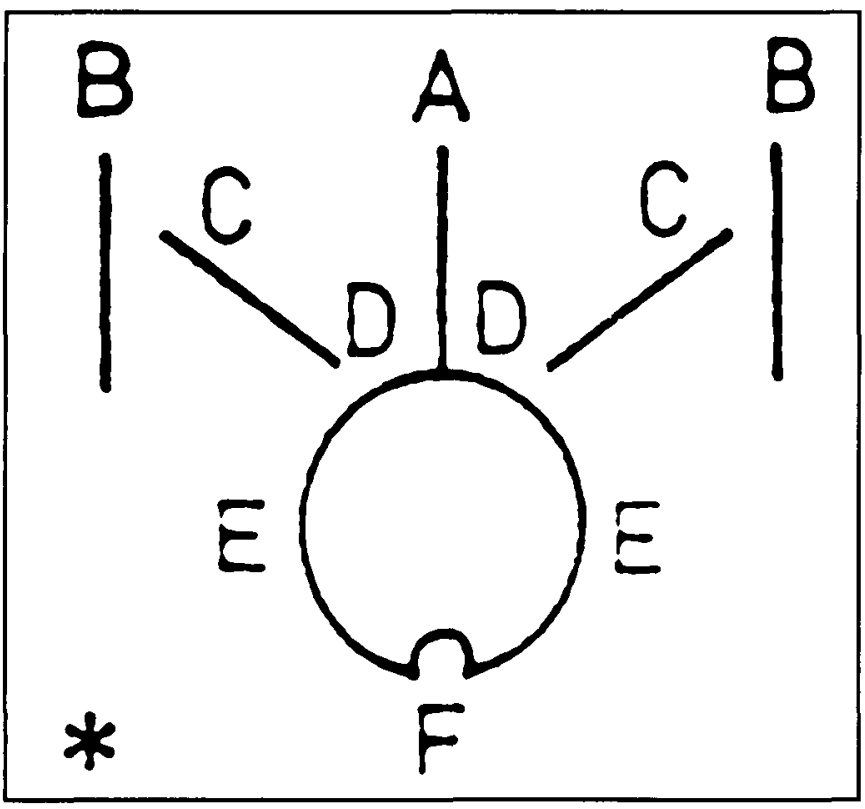

Figure 3: Identifies 10 basal cisterns and fissures: A. frontal interhemispheric fissure; B. sylvian fissure, lateral parts; $C$. sylvian fissure, basal. parts; D. suprasellar cistern; E. ambient cisterns; F. quadrigeminal cistern. (Adapted by permission from Hijdra, et al. Stroke 1990; 20: 11561165.)

The cisterns were graded from 0 to 3 with a score assigned to ten cisterns to give a potential score of 30 (lateral Sylvian fissures, basal Sylvian fissures, suprasellar cisterns, ambient cisterns, interhemispheric fissure and the quadrageminal plate cistern) (Figures 3-5).

The patients were graded based on the Hunt-Hess scale for SAH. ${ }^{16}$ The age, sex, site of aneurysm, and presence of premorbid hypertension were noted. Note was also made of those who had CSF drainage preoperatively, and those who eventually required post-operative shunting. No patients received antifibrinolytic agents.

Those patients who received external ventricular drainage as the method of pre-operative CSF diversion, had the drains placed at $10-15 \mathrm{~cm}$ above the external auditory meatus. The drains were placed in the open position and CSF flow was generally at $10 \mathrm{cc} / \mathrm{hr}$. The level of drain was not placed any lower than $10 \mathrm{~cm}$ due to the concern of altering the transmural pressure on the aneurysm. Most drains were placed at $15 \mathrm{~cm}$ above the external auditory meatus; if sufficient drainage of CSF occurred and the clinical status improved the level of the drain was not adjusted.

Each identified variable (age, sex, grade of SAH, site of aneurysm, premorbid hypertension, IV blood, IC blood, preoperative/perioperative CSF diversion, post-operative VP shunt) was subjected to a Chi Square analysis for the presence of acute hydrocephalus. Those variables identified as significant $(\mathrm{p}<0.05)$ were then combined and subjected to a multivariate regression model (Systatr $\vee 5.0$ Systat Inc) to determine the best overall model for prediction of the development of acute hydrocephalus from the data available. Forward step-wise regression with alpha to enter and alpha to remove of 0.15 was used.

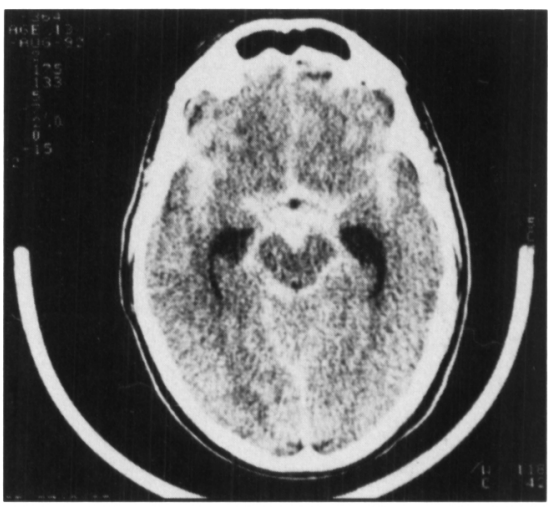

Figure 4: Illustrating CT scan of a patient with extensive cisternal blood post-subarachnoid hemorrhage.

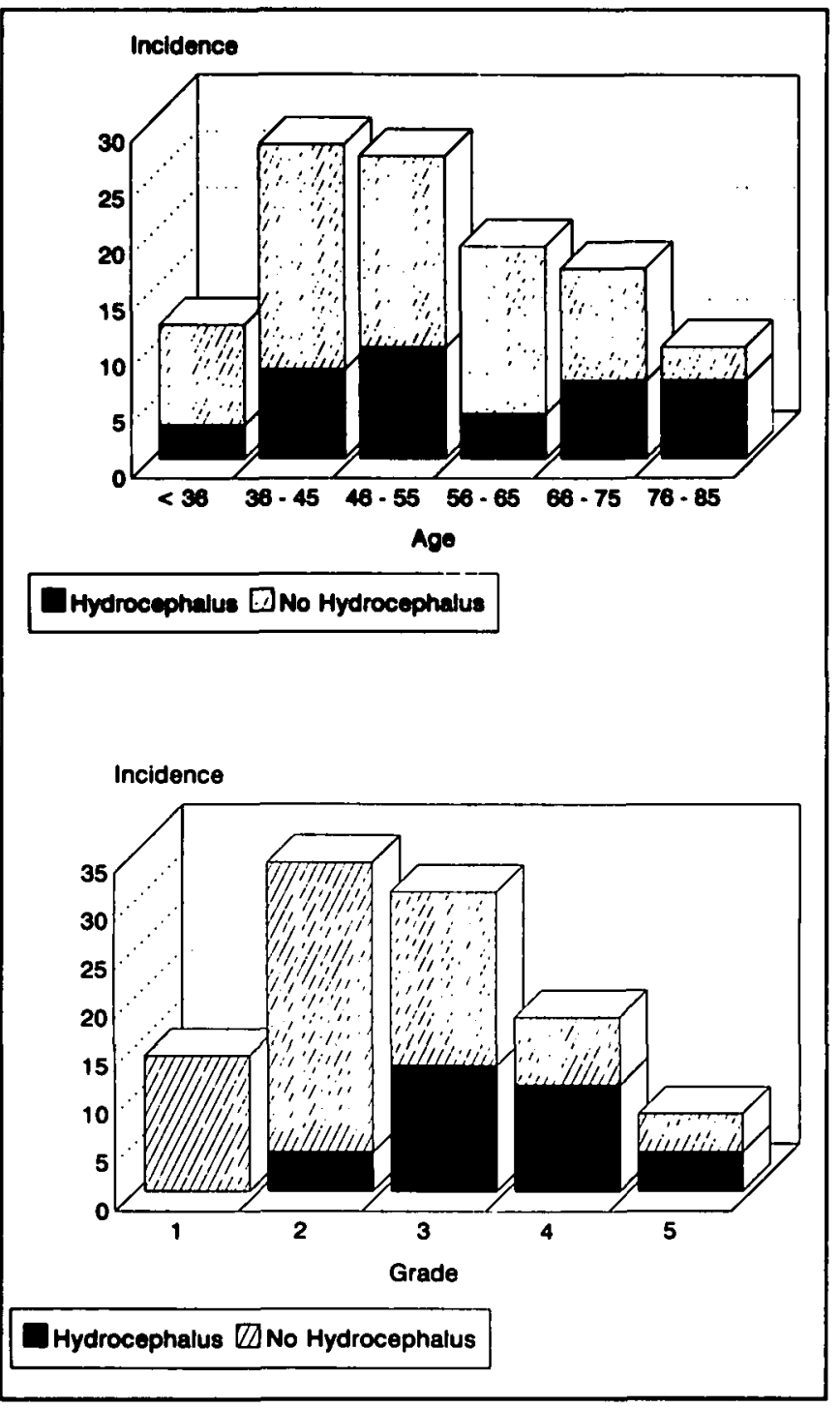

Figure 5: Graphs illustrating the relationship of both age and grade with acute hydrocephalus. 
Table 1: Patient information.

\begin{tabular}{|c|c|c|c|}
\hline & VARIABLE & NO HYDRO & HYDRO \\
\hline \# of patients & & 73 & 32 \\
\hline \multirow[t]{6}{*}{$\mathrm{AGE}$} & $<36$ & 9 & 3 \\
\hline & $36-45$ & 20 & 8 \\
\hline & $46 \cdot 55$ & 17 & 10 \\
\hline & $56-65$ & 15 & 4 \\
\hline & $66-75$ & 10 & 7 \\
\hline & $76-85$ & 3 & 7 \\
\hline \multirow[t]{2}{*}{ SEX } & Male & 31 & 13 \\
\hline & Female & 42 & 19 \\
\hline \multirow[t]{5}{*}{ GRADE of SAH } & 1 & 14 & 0 \\
\hline & 2 & 30 & 4 \\
\hline & 3 & 18 & 13 \\
\hline & 4 & 7 & 11 \\
\hline & 5 & 4 & 4 \\
\hline \multirow[t]{2}{*}{ SITE } & Ant. Circulation & 72 & 25 \\
\hline & Pos. Circulation & 1 & 7 \\
\hline \multirow[t]{5}{*}{ SITE } & Ant. Communicating & 29 & 12 \\
\hline & Middle Cerebral & 17 & 5 \\
\hline & A. Cereb./Pericallosal & 4 & 1 \\
\hline & Int. Carotid/P. Comm. & 22 & 7 \\
\hline & Posterior Circulation & 1 & 7 \\
\hline \multirow[t]{3}{*}{$\begin{array}{l}\text { INTRAVENTRIC. } \\
\text { BLOOD SCORE }\end{array}$} & $0-4$ & 68 & 19 \\
\hline & $5-8$ & 3 & 7 \\
\hline & $9-12$ & 2 & 6 \\
\hline \multirow[t]{3}{*}{$\begin{array}{l}\text { INTRACISTERNAL } \\
\text { BLOOD SCORE }\end{array}$} & $0-10$ & 26 & 1 \\
\hline & $11 \cdot 20$ & 15 & 7 \\
\hline & $21-30$ & 32 & 24 \\
\hline \multirow[t]{2}{*}{$\begin{array}{l}\text { PREMORBID } \\
\text { HYPERTENSION }\end{array}$} & NO & 63 & 24 \\
\hline & YES & 10 & 8 \\
\hline \multirow[t]{2}{*}{ CSF DIVERSION } & YES & 12 & 8 \\
\hline & NO & 61 & 5 \\
\hline \multirow[t]{2}{*}{ VP SHUNT } & NO & 71 & 24 \\
\hline & YES & 2 & 8 \\
\hline
\end{tabular}

Table 2: Univariate analysis of factors associated with the development of acute hydrocephalus following subarachnoid hemorrhage.

\begin{tabular}{lccc}
\hline VARIABLE & $\mathbf{r}^{2}$ & F Ratio & $\mathbf{p}$ \\
\hline AGE & .012 & 1.27 & .261 \\
\hline SEX & .031 & 3.4 & .068 \\
\hline GRADE & .059 & 6.6 & $<.05$ \\
\hline SITE - ANT. vS POST. CIRCULATION & .127 & 14.9 & $<.05$ \\
\hline SITE - SPECIFIC ARTERY & .003 & 0.28 & .596 \\
\hline INTRAVENTRICULAR BLOOD & .055 & 6.21 & $<.05$ \\
\hline INTRACISTERNAL BLOOD & .017 & 1.85 & .170 \\
\hline PREMORBID HYPERTENSION & .118 & 14 & $<.05$ \\
\hline PERIOPERATIVE CSF DIVERSION & .167 & 21.2 & $<.05$ \\
\hline VP SHUNT & .274 & 39 & $<.05$ \\
\hline
\end{tabular}

\section{Results}

Thirty-one percent of the patients who fulfilled our entry requirements for the study had evidence of acute hydrocephalus $(32 / 105)$. The demographics of the total patient population summarized in Table 1.

Results of the univariate analysis are shown in Table 2. Of the variables examined, grade of SAH, site (anterior versus posterior circulation), intraventricular blood, premorbid hypertension, pre-operative drainage and post-operative ventriculoperitoneal shunt were significantly associated with acute hydrocephalus. The results of the multivariate regression analysis are given in Table 3. Those factors found to be significant on multivariate analysis were: the presence of intraventricular blood, premorbid hypertension, preoperative/perioperative CSF drainage (EVD) and subsequent ventriculo-peritoneal shunting.

\section{DISCUSSION}

The incidence of acute hydrocephalus in this series was $31 \%$, slightly higher than previously reported ${ }^{3-6,15}$ Unlike the Cooperative study ${ }^{4}$ we found no statistically significant relationship between age and acute hydrocephalus. It has been proposed that in the older population the ventricles are already larger and less force is required to enlarge them further. The elderly subject may also have decreased CSF absorption secondary to meningeal fibrosis along the parasagittal portions of the cortex. ${ }^{17}$ Our review included only twenty-seven patients age sixtysix or older, and it is possible that our numbers were too small to show age as a significant factor. We found no relationship between gender and acute hydrocephalus.

The relationship between grade of hemorrhage and acute hydrocephalus was significant on univariate testing but not on multivariate analysis. The former is in keeping with clinical experience as the link between acute hydrocephalus and decreased level of consciousness is well established. ${ }^{3.15}$ Grade of $\mathrm{SAH}$ is associated with other factors such as intraventricular blood which directly contributes to the development of acute hydrocephalus.

Internal carotid, middle cerebral and posterior circulation artery aneurysms have been reported to be more often associated with the development of acute hydrocephalus. ${ }^{3,4.18}$ In our review the precise site of aneurysmal rupture was not related to acute hydrocephalus. However, when aneurysmal site was divided into anterior versus posterior circulation, posterior circulation aneurysms were significantly associated with the development of acute hydrocephalus. We did not examine the relationship of aneurysm site to the presenting blood pressure on admission (we did review premorbid hypertension). The Cooperative Study ${ }^{4}$ found that anterior communicating artery aneurysms and posterior circulation aneurysms were associated with higher presenting

Table 3: Multivariate linear regression analysis of factors identified by univariate analysis as predictive of the development of acute hydrocephalus.

\begin{tabular}{lccccc}
\hline FACTOR & COEFFICIENT & 2 STD. ERROR & TOLER & F & P \\
\hline GRADE & -.055 & & .683 & .307 & .58 \\
\hline IV BLOOD & -.243 & -.058 & .976 & .07 .8 & .00 \\
\hline HTN & .302 & .089 & .761 & .11 .6 & .00 \\
\hline CSF DIV & -.156 & -.156 & .902 & 30.3 & .00 \\
\hline VP & .551 & .551 & .931 & 30.6 & .00 \\
\hline
\end{tabular}


blood pressures. A ruptured anterior communicating artery aneurysm may cause sympathetic discharge from the hypothalamus whereas bleeding from posterior circulation aneurysms may obstruct CSF to cause 4th ventricular enlargement and pressure on the medulla. ${ }^{4}$

A history of premorbid hypertension was found statistically significant on both univariate and multivariate analysis when related to acute hydrocephalus. This was also found in the Cooperative Study. ${ }^{4}$ The development of hydrocephalus has been described in hypertensive rats by Ritter and Dinh, ${ }^{19}$ and the incidence of normal pressure hydrocephalus has been found to be increased in hypertensives. ${ }^{20}$

The occurrence of intraventricular blood has been shown to be associated with hydrocephalus and significant mortality. ${ }^{1.45 .52}$ We found the presence of intraventricular blood to be significantly associated with acute hydrocephalus. There was no significant relationship however between hydrocephalus and intracisternal blood. There is evidence to support and refute the relationship of cisternal blood to the development of acute hydrocephalus. ${ }^{3,15}$ Hasan et al., ${ }^{3}$ confirmed in the absence of ventricular blood, acute hydrocephalus was associated with a slightly higher amount of cisternal blood. In their series, $53 \%$ of 59 patients with acute hydrocephalus did not have ventricular blood and in this group the development of acute hydrocephalus was associated with the presence of blood in both ambient cisterns. We analyzed only the total extent of intracisternal blood and did not pay particular attention to whether or not cisternal blood was thicker in the ambient versus other cisterns.

CSF diversion, particularly external ventricular drainage (EVD) is used to combat acute hydrocephalus. Ten of twentyseven (10/27-37\%) survivors with acute hydrocephalus in this series had improvement of grade with EVD. None of these, or any other patients who had CSF diversion, suffered rebleeding. The concern over drainage procedures in this population relates to the alteration of transmural pressure in the aneurysm which may cause rebleeding. ${ }^{22.23} \mathrm{~A}$ number of studies have identified this occurrence in up to $43 \%$ of patients. ${ }^{6}$ Pare et al. reviewed 128 patients with SAH and found that the incidence of rebleeding was higher in those who had ventricular drainage, poor clinical grade and large aneurysm size. ${ }^{24}$ It has been postulated that those with radiographically defined hydrocephalus have a higher intracranial pressure and drainage in this group creates a greater increase in pressure across the aneurysm, and may lead to rerupture. Auer, et al. ${ }^{25}$ noticed a surprising lack of correlation between the extent of SAH and the level of intracranial pressure. We continue to use external ventricular drainage in those patients with poor clinical grade and acute hydrocephalus with favourable results.

Of our 27 survivors who presented with acute hydrocephalus, $8(29 \%)$ eventually required ventriculoperitoneal shunts. Six of these patients were shunted within 4-14 days of their initial $\mathrm{SAH}$ and 2 were shunted weeks to months later, having developed delayed onset hydrocephalus. Patients with excessive drainage through external ventricular drains postoperatively either went for shunting procedures or had their drain clamped. Those who changed clinically after clamping, or whose mean intracranial pressure rose consistently above $15 \mathrm{~mm} \mathrm{Hg}$, underwent shunting. Auer, et al. ${ }^{25}$ noted that there was no correlation between the amount of drainage through the external ventricular drain and the dependency of VP shunts in the postoperative aneurysm patient. In our experience, patients who required a ventriculoperitoneal shunt in the postoperative period had a significant incidence of acute hydrocephalus after their SAH.

In conclusion, we have shown in this retrospective analysis of 105 patients that the incidence of acute hydrocephalus following aneurysmal SAH was $31 \%$. Premorbid hypertension, intraventricular blood, CSF diversion and VP shunt were factors significantly related to acute hydrocephalus on multivariate analysis. Grade of SAH was significant on univariate testing but not on multivariate testing. In addition posterior circulation aneurysms were more often associated with acute hydrocephalus. We have not experienced any complications from preoperative external ventricular drainage for acute hydrocephalus. Those patients whose grade improves with external ventricular drainage are expedited to cerebral angiography and operative intervention.

\section{ACKNOWLEDGEMENTS}

We would like to thank Ms. Christine Crocker, Mrs. Mary Boudreau and Mr. Kelvin King for their help in preparing this document. Funding provided by the Department of Neurosurgery, Dalhousie University.

\section{REFERENCES}

1. Milhorat TH. Acute hydrocephalus. N Engl J Med 1970; 283: 857859.

2. Spallone A, Gagliandi FM. Hydrocephalus following aneurysmal subarachnoid hemorrhage. Zentralbl Neurochir 1983; 44: 141150.

3. Hasan D, Tanghe HLJ. Distribution of cisternal blood in patients with acute hydrocephalus after subarachnoid hemorrhage. Ann Neurol 1992; 31: 374-378.

4. Graff-Radford NR, Torner J, Adams HP, Kassell NF. Factors Associated with Hydrocephalus after Subarachnoid Hemorrhage. A Report of the Cooperative Aneurysm Study. Arch Neurol 1989; 46: 744-752.

5. Vassilouthis J, Richardson AE. Ventricular dilatation and communicating hydrocephalus following spontaneous subarachnoid hemorrhage. J Neurosurg 1979; 51: 341-351.

6. Hasan D, Vermeulen M, Wijdicks EFM, Hijdra A, van Gijn J. Management problems in acute hydrocephalus after subarachnoid hemorrhage. Stroke 1989; 20: 747-753.

7. Galera R, Greitz T. Hydrocephalus in the adult secondary to the rupture of intracranial arterial aneurysms. J Neurosurg 1970; 32: 634-640.

8. Raimondi AJ, Torres H. Acute hydrocephalus as a complication of subarachnoid hemorrhage. Surg Neurol 1973; 1: 23-26.

9. Black PM. Hydrocephalus and vasospasm after subarachnoid hemorrhage from ruptured intracranial aneurysms. Neurosurgery 1986; 18: 12-16.

10. Ellington E, Margolis G. Block of arachnoid villus by subarachnoid hemorrhage. J Neurosurg 1969; 30: 651-657.

11. Blasberg R, Johnson D, Fenstermacher J. Absorption resistance of cerebrospinal fluid after subarachnoid hemorrhage in the monkey: effects of heparin. Neurosurgery 1981; 9: 686-690.

12. Bagley C. Blood in the cerebrospinal fluid. Resultant functional and organic alterations in the central nervous system. Experimental data. Arch Surg 1928; 17: 18-38.

13. Doczi T, Nemiessanyi Z, Szegvary Z, Huszka E. Disturbances of cerebrospinal fluid circulation during the acute stage of subarachnoid hemorrhage. Neurosurgery 1983; 12: 435-438. 
14. Mancuso PA, Weinstein PR. Chapter 5G. Principles of management of subarachnoid hemorrhage: pathophysiology and management of hydrocephalus after subarachnoid hemorrhage. $m$ : Ratcheson RA, Wirth FP, eds. Ruptured Cerebral Aneurysms: Perioperative Management Vol. 6: Concepts in Neurosurgery. Williams \& Wilkins, 1994: 124-133.

15. Van Gijn J, Hijdra A, Wijdicks EFM, Vermeulen M, van Crevel $H$. Acute hydrocephalus after aneurysmal subarachnoid hemorrhage. J Neurosurg 1985; 63: 355-362.

16. Hunt WE, Hess RM. Surgical risk as related to time of intervention in the repair of intracranial aneurysms. J Neurosurg 1968;28: 14-20.

17. Hammes EM. Reaction of the meninges to blood. Arch Neurol Psychiatry 1944; 52: 505-514.

18. Yasargil MG, Yonekawa Y, Zumstein B, Stah HJ. Hydrocephalus following spontaneous subarachnoid hemorrhage. J Neurosurg 1973; 39: 474-479.

19. Ritter S, Dinh TT. Progressive postnatal dilatation of brain ventricles in spontaneously hypertensive rats. Brain Res 1986; 370: 327-332.
20. Graff-Radford NR, Godersky JC. Idiopathic normal pressure hydrocephalus and systemic hypertension. Neurology 1987; 37: 868871.

21. Mohr G, Ferguson G, Khan M, et al. Intraventricular hemorrhage from ruptured aneurysm. J Neurosurg 1983; 58: 482-487.

22. Nornes $H$. The role of intracranial pressure in the arrest of hemorrhage in patients with ruptured intracranial aneurysms. J Neurosurg 1973; 39: 226-234.

23. Heros RC, Kistler JP. Intracranial arterial aneurysm. An update. Stroke 1983; 14: 1-5.

24. Pare $L$, Delfino R, Leblanc R. The relationship of ventricular drainage to aneurysmal rebleeding. J Neurosurg 1992; 76: 422427.

25. Auer LM, Mokry M. Disturbed cerebrospinal fluid circulation after subarachnoid hemorrhage and acute aneurysm surgery. Neurosurgery 1990; 26: 804-809. 